\title{
Gamma-tocotrienol is required for normal vitamin D metabolism in female rats
}

\author{
M. Norazlina, F.W. Ng*, S. Ima-Nirwana
}

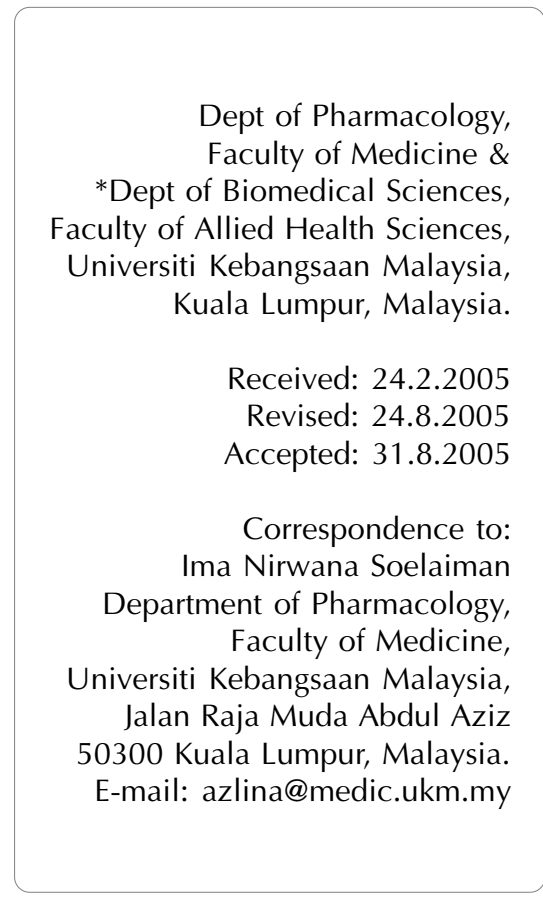

\begin{abstract}
Objective: To study the effects of vitamin E deficiency and supplementation of vitamin $\mathrm{D}$ and bone metabolism in female Sprague-Dawley rats.

Materials and Methods: Rats weighing between 200 and $250 \mathrm{~g}$ were divided into six groups, that is, rats fed on (a) normal rat chow diet (RC), (b) vitamin E-deficient diet (VED) (c) VED diet supplemented with $60 \mathrm{mg} / \mathrm{kg} \alpha$-tocopherol acetate (ATF), (d) VED diet supplemented with $60 \mathrm{mg} / \mathrm{kg} \gamma$-tocotrienol (GTT), (e) VED diet supplemented with $60 \mathrm{mg} / \mathrm{kg}$ Tocomin $^{\circledR}$ (TOC) and (f) baseline control group which was killed without treatment (BC). Treatment was given for 2 months. Serum 1,25-dihydroxyvitamin $D_{3^{\prime}}$ serum total calcium, urine calcium, left femur, and fourth lumbar vertebra calcium content and left femur length were measured.

Results: In the VED and ATF groups, activation of vitamin D to 1,25-dihydroxyvitamin $\mathrm{D}_{3}$ was inhibited and calcium reabsorption in the kidneys were increased. Both the effects seen in ATF and GTT groups were observed in the TOC group. The GTT group was protected from the effects of the vitamin E-deficient diet. Calcium content of the fourth lumbar vertebra was also decreased by vitamin E- deficiency, which was not reversed by vitamin E supplementation.

Conclusion: $\gamma$-tocotrienol and not $\alpha$-tocopherol protects vitamin $\mathrm{D}$ metabolism and calcium homeostasis from the effects of vitamin E-deficiency.
\end{abstract}

KEY WORDS: Calcium homeostasis, $\alpha$-tocopherol, vitamin E-deficiency.

\section{Introduction}

Vitamin D and its metabolites are among the factors that are important in regulating bone metabolism. Vitamin $\mathrm{D}_{3}$ is a prohormone, which is hydroxylated in the liver and in the kidney to the active metabolite 1,25-dihydroxyvitamin $\mathrm{D}_{3}$ and 24,25dihydroxyvitamin $\mathrm{D}_{3}$. In a previous study, supplementation with $\alpha$ 1, 25-dihydroxyvitamin $\mathrm{D}_{3}$ analogue was able to increase bone mineral density in osteoporotic women. ${ }^{[1]}$ The most potent vitamin $\mathrm{D}$ metabolite is 1,25-dihydroxyvitamin $\mathrm{D}_{3}$ (calcitriol), which stimulates calcium and phosphate transport from the intestine and calcium reabsorption from bone. ${ }^{|2|} 1,25-$ dihydroxyvitamin $\mathrm{D}_{3}$ has also been reported to act directly on circulating osteoclast precursors to influence osteoclast differentiation. ${ }^{[3]}$

Vitamin E, a lipid-soluble vitamin with antioxidant properties has an important role in protecting biological systems. There are two types of vitamin E; tocopherol and tocotrienol, and there are 4 isomers for each type: alpha $(\alpha)$, beta $(\beta)$, gamma $(\gamma)$ and delta $(\delta)$. Tocopherol has been shown to prevent lipid peroxidation ${ }^{[4]}$ and heart disease in postmenopausal women. ${ }^{[5]}$ Tocotrienol was shown to reduce carcinogenesis, ${ }^{[6]}$ and to inhibit the production of HMG-CoA reductase - the enzyme responsible for cholesterol synthesis. ${ }^{[7]}$

Palm oil is the major source of vitamin E, mainly the tocotrienol type. Vitamin E-rich extract from palm oil protected the bone against the toxic effects of the oxidizing agent ferric nitrilotriacetate, ${ }^{[8]}$ reduced bone resorption, and increased the survival rate of thyrotoxic rats ${ }^{[9]}$ and prevented the decline in bone mineral density, and bone calcium loss seen in orchidectomized rats. ${ }^{[10]}$

Palm vitamin E (60 mg/kg) was comparable to $\alpha$-tocopherol in maintaining bone mineral density and bone calcium content in ovariectomized rats. ${ }^{[1]}$ Tocotrienols and $\delta$-tocopherol were able to induce apoptosis in human mammary gland tumor cells. ${ }^{[12]}$ However, a few studies found that tocotrienol is superior compared to tocopherol. Alpha-tocotrienol was able to protect against glutamate-induced neuron cell death compared to $\alpha$-tocopherol. ${ }^{[13]}$ Palm vitamin E improved bone calcium content in vitamin $\mathrm{E}$ - deficient rats compared to $\alpha$ -

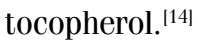


Vitamin E deficiency impaired calcification ${ }^{[15]}$ and retarded bone growth ${ }^{[16]}$ in normal and ovariectomized rats. Its mechanism is unclear. One hypothesis is that vitamin $\mathrm{E}$ deficiency may influence the hormones regulating bone metabolism (e.g., vitamin D metabolism). Other studies have shown that the presence of vitamin $\mathrm{E}$ is crucial in vitamin $\mathrm{D}$ metabolism and calcium absorption from the intestines in which they found that vitamin E deficiency reduced calcium absorption from the intestines ${ }^{[17]}$ and inhibited the conversion of vitamin D to its active metabolites. ${ }^{[18]}$ To further examine this hypothesis, this study was carried out, in which the effects of a vitamin E-deficient diet on vitamin D metabolism and bone calcium homeostasis were determined. The effects of supplementation with three different types of vitamin $\mathrm{E}$ on vitamin D metabolism were also studied.

\section{Materials and Methods}

\section{Animals and treatment}

Three-month old female Sprague-Dawley rats weighing 200 to $250 \mathrm{~g}$, obtained from the University Breeding Centre, were used. This study was a continuation of our previous study which used female rats, and for this study the gender of the animals was maintained. The rats were divided into 6 groups of 10 each: (1) control group fed normal rat chow diet (RC), and treatment groups fed with (2) vitamin E-deficient diet (VED), (3) vitamin E-deficient diet supplemented with $60 \mathrm{mg} / \mathrm{kg}$ pure $\alpha$-tocopherol acetate (ATF), (4) vitamin E-deficient diet supplemented with $60 \mathrm{mg} / \mathrm{kg} \gamma$-tocotrienol (GTT) and (5) vitamin E-deficient diet supplemented with $60 \mathrm{mg} / \mathrm{kg}$ Tocomin $^{\circledR}$ (TOC). The respective diets were given ad libitum. Treatment was carried out for 2 months. The sixth group, which acts as baseline control (BC), was untreated and was killed at the beginning of the study (day zero). This group acts as the control for bone calcium content and femur length. The other parameters were measured in either the serum or urine. For control values of these parameters, blood and urine were collected from each treatment group at day zero. Five rats were kept per cage under $12 \mathrm{~h}$ natural light/dark cycles and given distilled water ad libitum.

Diets

Normal rat chow was obtained from Gold Coin, Port Klang, Selangor, Malaysia. Vitamin E-deficient diet and $\alpha$-tocopherol acetate were purchased from ICN Biomedicals, Costa Mesa, CA, USA. The composition of rat chow diet and vitamin Edeficient diet are shown in Table 1 and 2, respectively. Gammatocotrienol, which contains $82 \% \gamma$-tocotrienol, and Tocomin ${ }^{\circledR}$ were supplied by Carotech Sdn Bhd, Ipoh Perak, Malaysia. Tocomin ${ }^{\circledR}$ contains $22.1 \% \gamma$-tocotrienol, $6.8 \% \delta$-tocotrienol, $10.7 \% \alpha$-tocotrienol, and $11.5 \% \alpha$-tocopherol. Vitamin $\mathrm{E}$ was dissolved in olive oil, produced by Bertolli Classico, Italy.

Alpha-tocopherol $(60 \mathrm{mg} / \mathrm{kg}$, body weight) was prepared by mixing $3 \mathrm{~g}$ of $\alpha$-tocopherol in $47 \mathrm{~g}$ olive oil. The same procedure was applied in preparing $\gamma$-tocotrienol and Tocomin ${ }^{\circledast}$ $(60 \mathrm{mg} / \mathrm{kg}$, b.w.). $0.1 \mathrm{~mL} / 100 \mathrm{~g}$ rat weight of the respective solutions was given by oral gavage 6 days a week for 2 months.

Bone and blood samples collection

Blood samples were taken before the start of treatment and at the end of treatment period. The rats were anesthetized with diethyl ether and blood was taken via the orbital sinus.

\section{Table 1}

Rat Chow diet composition (Gold Coin, Malaysia)

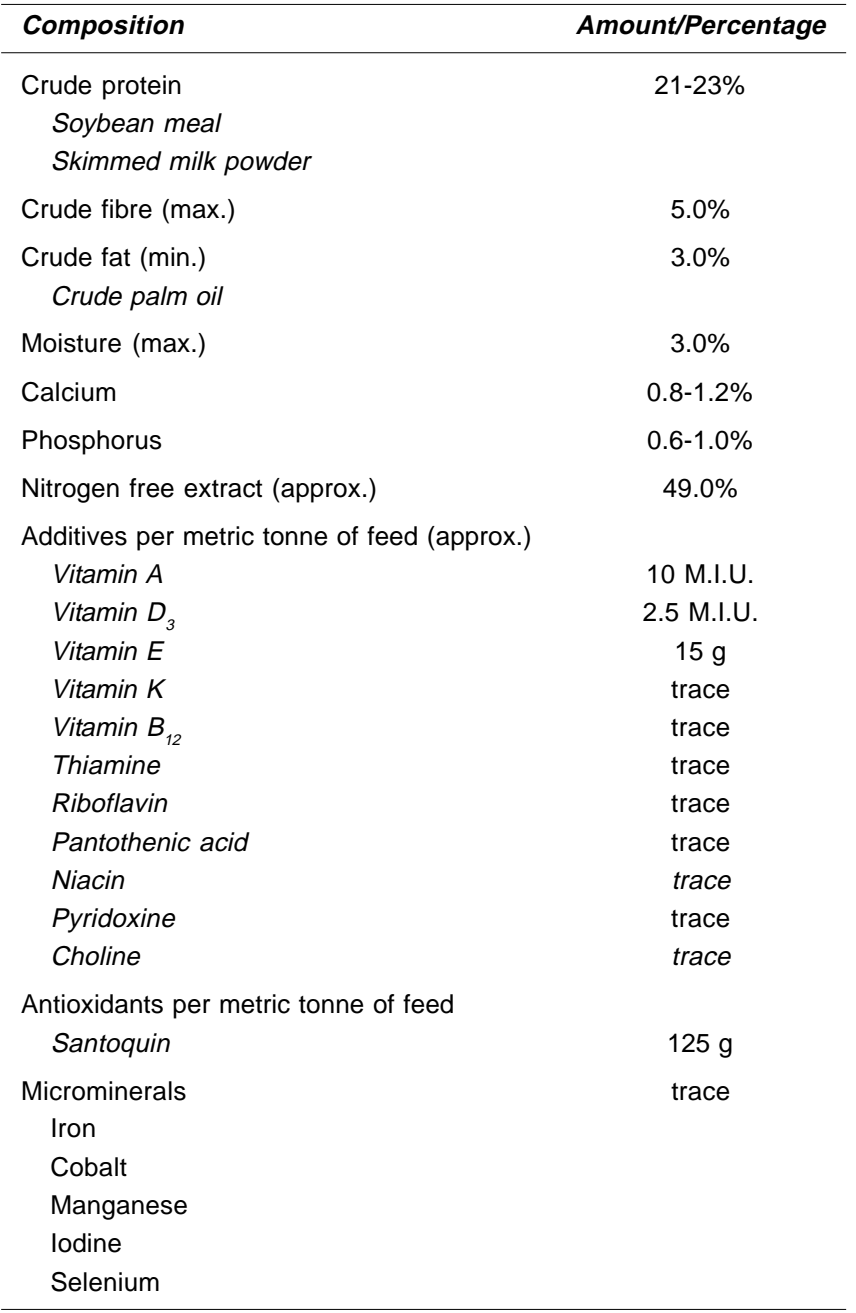

Serum was stored at $-70^{\circ} \mathrm{C}$ for the measurement of 1,25 dihydroxyvitamin $\mathrm{D}_{3}$ and calcium.

At the end of the treatment period, the rats were anesthetized and then sacrificed. Left femoral and $4^{\text {th }}$ lumbar bones were dissected out and cleansed of all soft tissues. Femur length was measured and the bones were then stored at $-70^{\circ} \mathrm{C}$ for the measurement of bone calcium content.

\section{Urine collection}

Urine samples were collected before the start of treatment and at the end of the treatment period. For this purpose, rats were placed in individual metabolic cages beginning at 4 o'clock in the afternoon until 80 'clock the next morning. Urine excreted during that period was collected and centrifuged at $3000 \mathrm{rpm}$ for $10 \mathrm{~min}$ at $4^{\circ} \mathrm{C}$. Hydrochloric acid $6 \mathrm{M}$ was added to the supernatant obtained until the final $\mathrm{pH}$ of the urine was less than 2.0 to dissolve the calcium ions in the urine.

\section{Serum 1,25-dihydroxyvitamin $D_{3}$ level}

Measurement was carried out using the ELISA kit from ImmunDiagnostik, Germany (catalog no. K2112). Color intensity, which reflects 1,25-dihydroxyvitamin $D_{3}$ concentration, was determined by using an ELISA reader (Tecan Spectra Classic, Austria). 


\section{Table 2}

Vitamin E-deficient diet composition (Draper et al)

\begin{tabular}{|c|c|}
\hline Composition & Fraction/Percentage \\
\hline Vitamin free casein & $20.0 \%$ \\
\hline Glucose & $66.0 \%$ \\
\hline Tocopherol deficient corn oil & $10.0 \%$ \\
\hline Salt mixture & $4.0 \%$ \\
\hline Sodium chloride & $11.88 \%$ \\
\hline Dibasic potassium phosphate & $8.5 \%$ \\
\hline Potassium carbonate & $8.75 \%$ \\
\hline Potassium sulphate & $4.98 \%$ \\
\hline Dibasic calcium phosphate & $39.11 \%$ \\
\hline Calcium carbonate & $18.5524 \%$ \\
\hline Magnesium carbonate & $5.89 \%$ \\
\hline Ferric citrate $(16-17 \% \mathrm{Fe})$ & $1.7555 \%$ \\
\hline Manganese sulphate. $\mathrm{H}_{2} \mathrm{O}$ & $0.41 \%$ \\
\hline Zinc carbonate & $0.1 \%$ \\
\hline Copper sulphate. $5 \mathrm{H}_{2} \mathrm{O}$ & $0.06 \%$ \\
\hline Sodium selenite & $0.000055 \%$ \\
\hline Potassium iodate & $0.0021 \%$ \\
\hline Chromium potassium sulphate. $12 \mathrm{H}_{2} \mathrm{O}$ & $0.01 \%$ \\
\hline Vitamin A acetate (500,000 I.U./gm) & $1.8 \mathrm{~g} / \mathrm{kg}$ \\
\hline Vitamin $D_{2}(850,000$ I.U./gm) & $0.125 \mathrm{~g} / \mathrm{kg}$ \\
\hline Ascorbic acid & $45.0 \mathrm{~g} / \mathrm{kg}$ \\
\hline Inositol & $5.0 \mathrm{~g} / \mathrm{kg}$ \\
\hline Choline chloride & $75.0 \mathrm{~g} / \mathrm{kg}$ \\
\hline Menadione & $2.25 \mathrm{~g} / \mathrm{kg}$ \\
\hline p-Amino benzoic acid & $5.0 \mathrm{~g} / \mathrm{kg}$ \\
\hline Niacin & $4.25 \mathrm{~g} / \mathrm{kg}$ \\
\hline Riboflavin & $1.0 \mathrm{~g} / \mathrm{kg}$ \\
\hline Pyridoxin hydrochloride & $1.0 \mathrm{~g} / \mathrm{kg}$ \\
\hline Thiamine hydrochloride & $1.0 \mathrm{~g} / \mathrm{kg}$ \\
\hline Calcium pantothenate & $3.0 \mathrm{~g} / \mathrm{kg}$ \\
\hline Biotin & $0.02 \mathrm{~g} / \mathrm{kg}$ \\
\hline Folic acid & $0.09 \mathrm{~g} / \mathrm{kg}$ \\
\hline Vitamin $\mathrm{B}_{12}$ & $0.00135 \mathrm{~g} / \mathrm{kg}$ \\
\hline
\end{tabular}

Serum and urine calcium levels

Total serum and urine calcium levels were measured on the basis of the complex produced because of the reaction between calcium and complexion o-cresol phthalein. This complex is purple in color and its intensity is related to calcium concentration. The intensity was determined photometrically using an ultra analyzer, Cobas Mira from Roche, USA.

Bone calcium content

Bone samples were left at room temperature for $24 \mathrm{~h}$, dried in an oven at $100{ }^{\circ} \mathrm{C}$ for $24 \mathrm{~h}$, then ashed in a furnace at $800^{\circ} \mathrm{C}$ for $12 \mathrm{~h}$. The ash was dissolved in $3 \mathrm{~mL} \mathrm{70 \%} \mathrm{nitric} \mathrm{acid} \mathrm{and}$ then diluted in lanthanum chloride $(12,500 \times$ dilution for the femur and $5000 \mathrm{x}$ dilution for the $4^{\text {th }}$ lumbar vertebra). Optical density was measured using flame atomic absorption spectrophotometer (Perkin Elmerä Instruments, USA). The calcium concentration was obtained from the standard curve. The amount of calcium per bone was then calculated by multiplying with the dilution factor.

This study was approved by the University's Research and Animal Ethics Committees and was carried out in accordance with the guidelines stated by the committees.

Analyses of data

Data from the same group, pre and post treatment were analyzed by paired t-test. One-way ANOVA and Dunnett's tests were used to compare data between different treatment groups. The significance level was set at $\mathrm{P}<0.05$. The results were presented as mean \pm SEM.

\section{Results}

Serum 1,25-dihydroxyvitamin $D_{3}$ level

1,25-dihydroxyvitamin $\mathrm{D}_{3}$ level for ATF and TOC groups were significantly reduced $(\mathrm{p}<0.05)$ upon completion of the study compared to the beginning of the study (Table 3). No significant differences between groups were observed at baseline. Percentage differences between, before, and after treatment were also not significantly different.

Table 3

The effects of vitamin $E$ deficiency and 3 different vitamin supplementations on serum 1,25-dihydroxyvitamin $D_{3}$ levels, total serum calcium levels and urine calcium levels

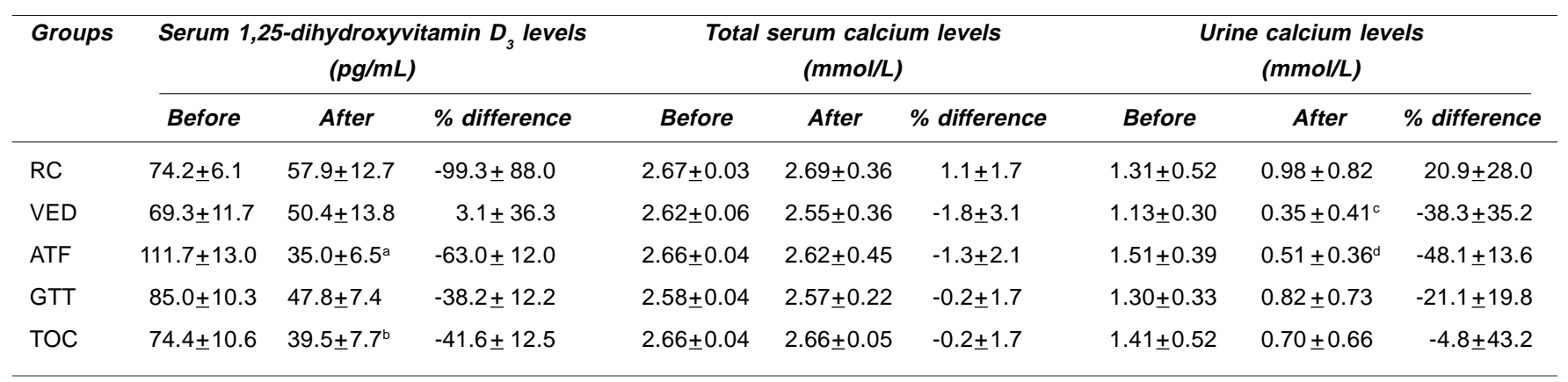

Values are mean \pm SEM, $\left(n=10\right.$ in each group. ${ }^{a, b, c, d}$ showed significant difference between before and after treatment of the same group. ${ }^{\text {a }} \mathrm{P}=0.003 ;{ }^{b} \mathrm{P}=0.024 ;{ }^{\mathrm{c}} \mathrm{P}=0.047$; ${ }^{\mathrm{d} P}=0.022$. RC - rat chow diet; VED - vitamin E-deficient diet; ATF - vitamin E-deficient diet supplemented with $\alpha$-tocopherol $60 \mathrm{mg} / \mathrm{kg}$; GTT - vitamin E-deficient diet supplemented with $\gamma$-tocotrienol $60 \mathrm{mg} / \mathrm{kg}$; TOC - vitamin E-deficient diet supplemented with Tocomin ${ }^{\circledR} 60 \mathrm{mg} / \mathrm{kg}$. \% difference is not significantly different between groups. 


\section{Table 4}

The effects of vitamin E deficiency and 3 different vitamin supplementations on femoral and 4th lumbar bone calcium content and femur length

\begin{tabular}{|c|c|c|c|}
\hline Groups & $\begin{array}{l}\text { Femur bone } \\
\text { calcium } \\
\text { content (mg) }\end{array}$ & $\begin{array}{c}4^{\text {th }} \text { lumbar bone } \\
\text { calcium } \\
\text { content }(\mathrm{mg})\end{array}$ & $\begin{array}{c}\text { Femur } \\
\text { length }(\mathrm{cm})\end{array}$ \\
\hline$B C$ & $79.4 \pm 3.7$ & $21.9 \pm 0.7$ & $3.21 \pm 0.02$ \\
\hline $\mathrm{RC}$ & $115.4 \pm 4.1^{\#}$ & $33.5 \pm 1.0^{\#}$ & $3.46 \pm 0.02^{\#}$ \\
\hline VED & $101.6 \pm 6.5$ & $24.2 \pm 1.7^{*}$ & $3.37 \pm 0.03^{\#}$ \\
\hline ATF & $101.5 \pm 4.1^{\#}$ & $27.5 \pm 1.5$ & $3.36 \pm 0.03^{\#}$ \\
\hline GTT & $103.9 \pm 3.9^{\#}$ & $26.4 \pm 1.2^{*}$ & $3.35 \pm 0.03^{\#}$ \\
\hline TOC & $102.5 \pm 5.2^{\#}$ & $28.1 \pm 1.2^{\#, *}$ & $3.36 \pm 0.03^{\#}$ \\
\hline One-way & 5.924 & 9.95 & 9.13 \\
\hline \multirow[t]{2}{*}{ ANOVA } & 57 & 56 & 58 \\
\hline & 0.000 & 0.000 & 0.000 \\
\hline
\end{tabular}

Values are mean + SEM, $n=10$ in each group. ${ }^{\#} \mathrm{P}<0.05$ when compared to $B C$ ${ }^{*} \mathrm{P}<0.05$ when compared to RC. BC - baseline control; RC - rat chow diet; VED - vitamin E-deficient diet; ATF - vitamin E-deficient diet supplemented with $\alpha$ tocopherol $60 \mathrm{mg} / \mathrm{kg}$; GTT - vitamin E-deficient diet supplemented with $\gamma$ tocotrienol $60 \mathrm{mg} / \mathrm{kg}$; TOC - vitamin E-deficient diet supplemented with Tocomin ${ }^{\circledR}$ $60 \mathrm{mg} / \mathrm{kg}$

\section{Total serum calcium level}

As shown in Table 3, no significant difference was seen in total serum calcium levels between groups at baseline and completion of study. No significant difference was also observed between the baseline and final data for each group, as well as the percentage differences between them.

Urine calcium level

The urine calcium concentrations in the VED and ATF groups were lower $(\mathrm{P}<0.05)$ at completion of the study compared to the baseline value (Table 3). No significant differences between the groups were observed at baseline. Similar findings were observed in the percentage differences between, before, and after treatment.

\section{Bone calcium content}

Table 4 shows the results of the bone calcium content assay. All groups except VED had a significantly higher femur bone calcium content compared to baseline control $(\mathrm{P}<0.05)$. As for lumbar bone calcium content, only the RC and TOC groups showed higher values $(\mathrm{P}<0.05)$ compared to $\mathrm{BC}$. The rest of the groups were comparable to $\mathrm{BC}$. In addition to that, the VED, GTT and TOC groups had lower lumbar bone calcium content $(\mathrm{P}<0.05)$ as compared to $\mathrm{RC}$ group.

\section{Femur length}

The differences in femur length between groups are shown in Table 4. All the groups had a significantly longer femur bone as compared to $\mathrm{BC}$ group $(\mathrm{P}<0.05)$.

\section{Discussion}

Our previous study showed that vitamin E deficiency caused hypocalcemia in rats as early as the first month of treatment; ${ }^{[19]}$ however, calcium levels were almost back to normal in the second month. We also found that secretion of parathyroid hormone was increased in the second month and it stimulated bone resorption and corrected hypocalcemia. On the basis of our findings in the previous study, we fixed the treatment duration for the present study at 2 months because biochemical changes are likely to occur within this period. In the present study, no significant difference in serum calcium level can be seen between the treatment groups. As per the results of our previous study, hypocalcaemia, which may have occurred, was probably corrected by the second month. Studies have shown that vitamin E deficiency-induced disturbances in calcium transport from the intestine ${ }^{[17]}$ were due to the inhibition of the conversion of vitamin D to its active metabolites. ${ }^{[18]}$ These researchers also found that the rats showed a decreased level of 1,25-dihydroxyvitamin $\mathrm{D}_{3}$. Although the study by Sergeev et al. (1990) ${ }^{[18]}$ failed to show an increase in parathyroid hormone level, our study showed the opposite. ${ }^{[19]}$ However, the treatment period and the time point at which parathyroid hormone levels were measured might have been different between these two studies.

Our present study measured total serum calcium, which might not accurately reflect the ionized calcium level. Vitamin $\mathrm{E}$ deficiency might affect levels of plasma proteins, although there is no evidence to support this; therefore in future studies, measurement of ionized calcium might be more meaningful. Measurement of phosphorus levels should also be considered because phosphorus is another major mineral which contributes to bone density and bone growth.

In the present study, no significant difference in serum 1,25dihydroxyvitamin $\mathrm{D}_{3}$ level was observed between all groups at baseline and upon completion of the study. However, upon within group comparison, the ATF and TOC groups showed a significant decrease in serum 1,25-dihydroxyvitamin $\mathrm{D}_{3}$ levels after treatment compared to baseline values. Low levels of 1,25-dihydroxyvitamin $\mathrm{D}_{3}$ in ATF and TOC groups suggests that vitamin $\mathrm{E}$ deficiency inhibit the activation of vitamin $\mathrm{D}$, and supplementing with ATF or TOC did not overcome the inhibition. The observation that no significant change in 1,25dihydroxyvitamin $\mathrm{D}_{3}$ levels before and after treatment for the VED group suggests that after 2 months, some compensatory mechanisms enabled the metabolism of vitamin $\mathrm{D}$ to return to normal. The inability of the ATF or TOC groups to normalize the 1, 25-dihydroxyvitamin $\mathrm{D}_{3}$ levels after 2 months suggest inhibition of the compensatory mechanism that counteract the effects of vitamin $\mathrm{E}$ deficiency. The compensatory mechanism, which is responsible for this phenomenon, need further studies.

In contrast, results in the GTT group suggests that supplementation with $\gamma$-tocotrienol alone was not inhibitory and may even aid in normalizing the vitamin D metabolism. Thus, the inhibitory effect of the TOC supplementation was probably due to its $\alpha$-tocopherol component.

Urine calcium was found to be decreased in the VED and ATF groups post-treatment compared to baseline. Because vitamin $\mathrm{E}$ deficiency inhibited the activation of vitamin $\mathrm{D},{ }^{[18]}$ and 1,25-dihydroxyvitamin $\mathrm{D}_{3}$ is needed for optimum intestinal calcium absorption, these data suggests that hypocalcemia was induced in all the vitamin E-deficient groups. However, the group supplemented with GTT was able to correct its 
hypocalcemia by the second month, thereby resulting in the normal serum and urine calcium levels. This was probably because supplementation with $\gamma$-tocotrienol allowed for the activation of vitamin D. However, for the VED and ATF groups, urine calcium was low, suggesting that supplementation with $\alpha$-tocopherol alone was not effective in normalizing calcium homeostasis. Probably an increased calcium reabsorption by the kidneys occurred in compensation. For the ATF group, the low levels of serum 1,25-dihydroxyvitamin $\mathrm{D}_{3}$ made this problem worse. In the TOC group, a combination of the effects of $\gamma$-tocotrienol and $\alpha$-tocopherol were seen, that is, serum 1,25-dihydroxyvitamin $\mathrm{D}_{3}$ was low, but urinary calcium concentration was normal.

Tocotrienols are less excreted compared to tocopherols ${ }^{|20|}$ and its protective effects against vitamin E deficiency may be prolonged. Others have found that vitamin E deficiency reduced the $\alpha$-tocopherol binding protein in liver. ${ }^{[1]}$ This may explain the lower efficacy of $\alpha$-tocopherol compared to palm tocotrienol.

Tocomin ${ }^{\circledR}$ supplementation caused a reduction in 1,25 dihydroxyvitamin $\mathrm{D}_{3}$ level as in the ATF group and showed comparable effect on urine level of calcium as in GTT group. Tocomin ${ }^{\circledR}$ contains $22.1 \% \gamma$-tocotrienol and $11.5 \% \alpha$-tocopherol. This composition of Tocomin ${ }^{\circledR}$ may have caused the mixed effects seen in the serum 1,25-dihydroxyvitamin $\mathrm{D}_{3}$ level and urine calcium level. This implies that supplementation of GTT alone is superior to that of the mixture of $\alpha$-tocopherol and $\gamma$ tocotrienol. Furthermore, the quantity of GTT present in Tocomin ${ }^{\circledR}$ is lower than the pure $\gamma$-tocotrienol thus, diminishing its effects. Furthermore, the presence of $\alpha$-tocopherol in TOC may contribute to its lower efficacy. Therefore, the overall picture seen with TOC supplementation will depend on the dominant isomer, as well as on the duration of treatment.

Our findings also suggest that $\alpha$-tocopherol and $\gamma$ tocotrienol might act via different pathways to influence vitamin D metabolism and calcium homeostasis. Another possible explanation is that the tissue distribution of these forms of vitamin $\mathrm{E}$ varies between each other and exerts its action on different tissues depending on their distribution. One study showed that the distribution of tocotrienol and tocopherol is tissue specific. ${ }^{[22]}$

In the present study, the serum parameters were measured at the beginning and at the end of the treatment period. Any differences in the parameters levels, which may occur between these two time-points, might be overlooked. It is highly recommended that a time-course measurement be done in future studies.

Vitamin E deficiency (VED group) impaired calcification of both femur and fifth lumbar vertebra bones as compared to BC suggesting an impaired calcification or calcium loss. However, the lumbar bone calcium content of the VED group, but not femur, differed significantly compared to RC. This is in agreement with our previous study and the bone loss observed may be due to bone resorption induced by secondary hyperparathyroidism. ${ }^{[19]}$ Furthermore, inhibition of vitamin D metabolism is known to impair calcium absorption from the intestine; therefore less calcium was available for deposition into bone.
Lumbar vertebral bones consist mainly of cancellous bone, while femoral bones contain more cortical bone. Cancellous bone has a higher metabolic and remodeling rate compared to cortical bone, and therefore, the lumbar vertebral bones are more affected by any stress or changes compared to femoral bones. ${ }^{\mid 23]}$ Cancellous bone has a higher ratio of bone surface area to bone volume compared to cortical bone. Bone remodeling occurs on the bone surface; hence cancellous bone metabolic rate is tenfold higher than cortical bone. ${ }^{[24]}$ As a result, the effects of vitamin $\mathrm{E}$ deficiency on bone calcium content were more apparent in the lumbar vertebral bones as compared to the femoral bones.

The RC group showed an increase in the femur and lumbar bone calcium content as compared to the BC group indicating that the rats were growing. Bone calcium content of the VED group did not increase compared to $\mathrm{BC}$ and the lumbar bone calcium content was lower than RC. This suggests that vitamin E deficiency impaired bone calcification. Femur bone calcium content in the vitamin E supplemented groups did not differ compared to VED.

In the lumbar bones, GTT and TOC group failed to increase its bone calcium content to the level of RC although GTT group was able to maintain biochemical parameters comparable to the RC group. The short treatment period may not be sufficient for GTT to reverse the effects of vitamin E deficiency on bone calcium content. Previous studies showed that palm vitamin E supplementation prevented bone calcium loss in rats exposed to ferric-nitrilotriacetate, an oxidizing agent. ${ }^{[8]}$ Palm oil has high quantity of tocotrienol and any protective effects shown by palm vitamin $\mathrm{E}$ is probably due to its tocotrienol component. Another study showed that palm vitamin E supplementation, but not $\alpha$-tocopherol, at the dose of 30 and $60 \mathrm{mg} / \mathrm{kg}$ for 8 months was able to increase bone calcium content in vitamin E-deficient rats. ${ }^{[14]}$ The beneficial effects of GTT on bone calcium in this study could have been more obvious had the study period been longer. ATF supplementation seemed to improve lumbar bone calcium content, but this group failed to normalize the levels of biochemical parameters (serum 1,25dihydroxyvitamin $\mathrm{D}_{3}$ and urine calcium) even after 2 months. The long-term impact needs to be elucidated in further studies.

Longitudinal growth of the femur in all of the groups was increased compared to the BC group. The differences in femur length observed in this study were almost the same as the femur bone calcium content results. No difference was seen between the VED group and the vitamin E supplemented groups. However, a study done in chicks found that vitamin $\mathrm{E}$ improved bone growth by increasing the thickness of the growth plate cartilage. ${ }^{[25]}$

\section{Conclusion}

Our data indicates that vitamin E deficiency inhibits activation of vitamin D, which leads to hypocalcaemia and bone loss. Supplementation with $\gamma$-tocotrienol $60 \mathrm{mg} / \mathrm{kg}$ rat weight, but not $\alpha$-tocopherol $60 \mathrm{mg} / \mathrm{kg}$ rat weight or a mixture of $\alpha$ tocopherol and the tocotrienols as in Tocomin ${ }^{\circledR}$, preserved vitamin D metabolism and maintained calcium homeostasis. Therefore, gamma-tocotrienol and not alpha-tocopherol protects female rats from the effects of vitamin E deficiency 
on vitamin D metabolism; however, it does not prevent a decline in lumbar vertebra calcium content over a 2-month period.

\section{Acknowledgments}

The authors would like to thank Universiti Kebangsaan Malaysia for the research grant FF-012-2002. We also thank carotech Sdn Bhd for supplying gammatocotrienol and Tocomin ${ }^{\circledast}$ needed for the study. We express our gratitude to $\mathrm{Mr}$. Mohd Imran Mohd Ali and Pn Azizah Osman for their technical assistance.

\section{References}

1. Shikari M, Kushida K, Yamazaki K, Nagai T, Inoue T, Orimi H. Effects of 2 years' treatment of osteoporosis with 1 alpha-hydroxyvitamin $D_{3}$ on bone mineral density and incidence of fracture: A placebo-controlled, double blinded prospective study. Endocrinol J 1996;43:211-20.

2. Bikle DD. Agent that affect bone mineral homeostasis. In: Katzung BG, editor. Basic and Clinical Pharmacology, 8th ed. New York: McGraw-Hill, 2001. p. 735-54.

3. Itonaga I, Sabokbar A, Neale SD, Athanasou NA. 1,25-dihydroxyvitamin $D_{3}$ and prostaglandin $E_{2}$ act directly on circulating human osteoclast precursors. Biochem Biophys Res Commun 1999;264:590-5.

4. Princen HMG, Duyvenvoorde WV, Buytenhek R, Laarse AVD, Poppel GV, Gevers-Leuven JA, et al. Supplementation with low doses of vitamin E protects LDL from lipid peroxidation in men and women. Arterioscler Thromb Vasc Biol 1995;15:325-33.

5. Inal M, Sunal E, Kanbak G, Zeytinoglu S. Effects of postmenopausal hormone replacement therapy and $\alpha$-tocopherol on the lipid profiles and antioxidant status. Clin Chimica Acta 1997;268:21-9.

6. Ngah WW, Jarien Z, San MM. Effect of tocotrienols on hepatocarcinogenesis induced by 2-acetylaminofluorene in rats. Am J Clin Nutr 1991;53:1076-81.

7. Khor HT, Chieng DY, Ong KK. Tocotrienols inhibit liver HMG-CoA reductase activity in guinea pig. Nutr Res 1995;15:537-44.

8. Yee JK, Ima-Nirwana S. Palm vitamin E protects against ferric-nitrilotriacetateinduced impairment of bone calcification. Asia Pacific J Pharmacol 1998;13: $1-7$.

9. Ima-Nirwana S, Kiftiah A, Sariza T, Gapor MT, Khalid BAK. Palm vitamin E improves bone metabolism and survival rate in thyrotoxic rats. General Pharmacol 1999;32:621-6.

10. Ima-Nirwana S, Kiftiah A, Zainal AG, Norazlina M, Abdul-Gapor MT, Khalid BAK. Palm vitamin $E$ prevent osteoporosis in orchidectomized growing male rats. Natural Product Sciences 2000;6:155-60.
11. Norazlina M, Ima-Nirwana $S$, Abdul-Gapor MT, Khalid BAK. Palm vitamin E is comparable to $\alpha$-tocopherol in maintaining bone mineral density in ovariectomised female rats. Exp Clin Endocrinol Diabetes 2000;108:305-10.

12. Yu W, Simmons-Menchaca M, Gapor A, Sanders BG, Kline K. Induction of apoptosis in human breast cancer cells by tocopherols and tocotrienols. Nutr Cancer 1999;33:26-32.

13. Sen CK, Khanna S, Roy S, Packer L. Molecular basis of vitamin E action. Tocotrienol potently inhibits glutamate-induced pp60 (c-Src) kinase activation and death of HT4 neuronal cells. J Bio Chem 2000;275:13049-55.

14. Norazlina M, Ima-Nirwana S, Abdul-Gapor MT, Khalid BAK. Tocotrienols are needed for normal bone calcification in growing female rats. Asia Pacific J Clin Nutr 2002:11:194-9.

15. Norazlina M, Ima-Nirwana S, Khalid BAK. Effects of vitamin E deficiency on bone metabolism in intact and ovariectomised growing female rats. Asia Pacific J Pharmacol 2001;15:37-46.

16. Ima-Nirwana S, Norazlina M, Gapor MT, Khalid BAK. Vitamin E deficiency impairs weight gain in normal and ovariectomised growing female rats. Med J Islamic Academy Sciences 2002;12:89-96.

17. Sergeev IN, Kha KP, Blazheerich NV, Spirichev VB. Effects of combined vitamin $\mathrm{E}$ and $\mathrm{D}$ deficiencies on calcium metabolism and bone tissue of the rat. Vopr Pitan 1987;1:39-43.

18. Sergeev IN, Arkhapchev IP, Spirichev VB. The role of vitamin E in metabolism and reception of vitamin D. Biokhimiia 1990;55:1989-95.

19. Norazlina M, Chua CW, Ima-Nirwana S. Vitamin E deficiency reduced lumbar bone calcium content in female rats. Med J Malaysia 2004;59:623-30.

20. Lodge JK, Ridlington J, Leonard S, Vaule H, Traber MG. Alpha- and gammatocotrienols are metabolized to carboxyethyl-hydrochroman derivatives and excreted in human urine. Lipid 2001;36:43-8.

21. Shaw HM, Huang CJ. Liver $\alpha$-tocopherol transfer protein and its mRNA are differently altered by dietary vitamin $\mathrm{E}$ deficiency and protein insufficiency in rats. J Nutr 1998;128:2348-54.

22. Podda M, Weber C, Traber MG, Packer L. Simultaneous determination of tissue tocopherols, tocotrienols, ubiquinols and ubiquinones. J Lipid Res 1996;37:893901.

23. Buckwalter JA, Glimcher MJ, Cooper RR, Recker R. Bone biology, Part II: Formation, form, modeling, remodeling and regulation of cell function (Instructional Course Lecture) Bone Joint Surg 1995;77-A:1276-89.

24. Kanis JA. Requirements for calcium and its use in the management of osteoporosis. In Stevenson JC, Lindsay R, editors. Osteoporosis. London: Chapman \& Hall Ltd.; 1998. p. 215-42.

25. Xu H, Watkins BA, Seifert MF. Vitamin E stimulates trabecular bone formation and alters epiphyseal cartilage morphometry. Calcif Tissue Int 1995;57:293300.

\title{
IPS WEBSITE
}

\section{IPS has launched a website \\ www.gsips.org}

Features: Online registration, Constitution and Member list at one click.

\section{Contact point:}

\author{
Dr. Prakash V. Diwan \\ General Secretary, IPS \\ Head, Pharmacology Division \\ Indian Institute of Chemical Technology \\ Hyderabad -500 007 \\ E.mail: diwan@iict.res.in, diwan_prakash@rediffmail.com
}

